\title{
Investigating the Performances of Direct Torque and Flux Control for Dual Stator Induction Motor with Direct and Indirect Matrix Converter
}

\author{
Yahia Moati ${ }^{*}$, Katia Kouzi $^{1}$ \\ 1 Laboratory of Semiconductors and Functional Materials, Amar Telidji University of Laghouat, \\ P. O. B. 37G, Route de Ghardaïa, Laghouat 03000, Algeria \\ * Corresponding author, e-mail: y.moati@lagh-univ.dz
}

Received: 14 September 2019, Accepted: 22 October 2019, Published online: 07 December 2019

\begin{abstract}
This work investigates the performances of Direct Torque Control (DTC) of Dual Stator Induction Motor (DSIM) powered by two types of Matrix Converter (MC), namely the direct and indirect MC. To this end, the design of DTC with conventional Direct Matrix Converter (DMC) is firstly presented. Then, in order to illustrate the main feature of Indirect Matrix Converter (IMC) in terms of the output voltages and input currents waveforms, the full steps of IMC are well explained. To discuss the performance of each scheme, both techniques are simulated in the Matlab/Simulink environment for a $4.5 \mathrm{~kW}$ DSIM at different operating conditions. The obtained results show that the IMC provides high performance in torque and flux at different conditions and while minimization the Total Harmonic Distortion (THD) in the input current compared by the conventional DMC.
\end{abstract}

\section{Keywords}

Double Stator Induction Motor (DSIM), Direct Torque Control (DTC), Direct Matrix Converter (DMC), Indirect Matrix Converter (IMC), Space Vector Modulation (SVM)

\section{Introduction}

Multiphase machines exist as alternatives to the conventional three-phase machines to cover various undertakings, exceptional benefits such that the power split between the different phases, high dependability, reduced rotor losses, and torque ripples. Such advantages make the multiphase machine very favored in various fields in recent years [1,2].

Among of these multiphase machines and the most common is the DSIM. The modeling, analysis and several advanced control strategies of this machine, comprise the direct torque control (DTC), field oriented control (FOC) and model predictive control (MPC), etc., have been applied to the DSIM. Recent research improvements in the control of DSIM and comparison of some control strategies have been reviewed in [3, 4]. Among of the many powerful techniques used for the control of the DSIM is the DTC technique that was proposed by Takahashi in [5], it is characterized by the fast dynamic, simple structure, simple decoupled scheme between the electromagnetic torque control and stator flux and the robustness [6, 7].

The $\mathrm{MC}$ is an $\mathrm{AC} / \mathrm{AC}$ converter that has the advantage of being free of the bulky dc-link capacitor that exists in other $\mathrm{AC} / \mathrm{AC}$ topologies. The $\mathrm{MC}$ has existed to cover different tasks and satisfy some requirements such as; a sinusoidal waveform of input and output currents with adjustable amplitude and frequency, a unity input power factor and a bidirectional power flow. The MC can be invested to take profit of its great benefits compared to the conventional inverters $[8,9]$.

The first research studies on the MC amount to the work of Venturini and Alesina. In the late 1980's and early 1990's [10, 11]. A few researchers in presented space Vector Modulation (SVM) and Indirect Space Vector Modulation (ISVM) [12, 13]. A survey of MC research is suggested in and the adjustment techniques are presented in $[8,9]$. "Casadei" firstly exhibited the use of MC in the DTC in [14]. In his work, it is shown that the MC offers addition to the flux and torque regulation. This strategy has been stretched out to the IMC in $[15,16]$.

Some research results about the DTC applied to the DSIM via a matrix converter has been presented for the aim to improve the dynamics, reduce the flux, and torque undulation [17-19]. This study aims to do a comparative 
study between two types of MC, namely the direct and indirect $\mathrm{MC}$, in terms of performance of DTC for the DSIM. This comparative study particularly focuses on the waveforms of the voltages and currents, the THD of the input current and the electromagnetic performances.

The remainder of this paper is as follows: Section 2 presents modeling of the system (DSIM and MC) Section 3 shows the principle of the DTC for the DSIM. In Section 4, the DTC oriented to both DMC and IMC is presented. Section 5 presents a simulation study, which illustrates the robust performance of IMC. Finally, conclusion and perspectives are given in Section 6.

\section{Modeling of the system}

\subsection{The DSIM model}

The DSIG consists of a stator contain two identical threephases windings displaced by an electric angle $\gamma\left(\gamma=30^{\circ}\right)$ and a squirrel cage rotor. With the distribution of its windings and its own geometry, is very complex to lend itself to an analysis taking into account its exact configuration. It is then necessary to adopt certain simplifying hypotheses such that: The machine is supposed to be "linear", that is to say that the saturation and the hysteresis effects of the magnetic circuits are neglected as well as the phenomenons causing variations of resistances and inductance, the magnetomotive air gap force produced by each winding is assumed to have a sinusoidal spatial distribution, which amounts to neglecting space harmonics, the air gap is of constant width, and it is assumed that the two three-phase stator windings are balanced and identical $[1,2]$. Seeing that the preference of the reference $(\mathrm{dq})$ related to the rotating field, a facilitation of the DSIM term is gained by writing a next consolidated form. The model of the machine is expressed by state space representation as follow [20-22]:

$\frac{d X}{d t}=A X+B U$

where

$X=\left[\begin{array}{llllll}\varphi_{d s 1} & \varphi_{d s 2} & \varphi_{q s 1} & \varphi_{q s 2} & \varphi_{d r} & \varphi_{q r}\end{array}\right]^{T}$

is the vector of state space,

$U=\left[\begin{array}{llllll}V_{d s 1} & V_{d s 2} & V_{q s 1} & V_{q s 2} & 0 & 0\end{array}\right]^{T}$

is the vector control.

Then, the matrices $A$ and $B$ are determinate by:

$$
A=\left[\begin{array}{cccccc}
-\frac{R_{s 1}}{L_{s 1}}+\frac{R_{s 1} L_{a}}{L_{s 1}^{2}} & \frac{R_{s 1} L_{a}}{L_{s 1} L_{s 2}} & \omega_{s} & 0 & \frac{R_{s 1} L_{a}}{L_{r} L_{s 1}} & 0 \\
\frac{R_{s 2} L_{a}}{L_{s 1} L_{s 2}} & -\frac{R_{s 2}}{L_{s 2}}+\frac{R_{s 2} L_{a}}{L_{s 2}^{2}} & 0 & \omega_{s} & \frac{R_{s 2} L_{a}}{L_{r} L_{s 2}} & 0 \\
-\omega_{S} & 0 & -\frac{R_{s 1}}{L_{s 1}}+\frac{R_{s 1} L_{a}}{L_{s 1}^{2}} & \frac{R_{s 1} L_{a}}{L_{s 1} L_{s 2}} & 0 & \frac{R_{s 1} L_{a}}{L_{r} L_{s 1}} \\
0 & -\omega_{S} & \frac{R_{s 1} L_{a}}{L_{s 1} L_{s 2}} & -\frac{R_{s 2}}{L_{s 2}}+\frac{R_{s 2} L_{a}}{L_{s 2}^{2}} & 0 & \frac{R_{s 1} L_{a}}{L_{r} L_{s 2}} \\
\frac{R_{r} L_{a}}{L_{r} L_{s 1}} & \frac{R_{r} L_{a}}{L_{r} L_{s 2}} & 0 & 0 & -\frac{R_{r}}{L_{r}}+\frac{R_{r} L_{a}}{L_{r}^{2}} & -\left(\omega_{s}-\omega_{r}\right) \\
0 & 0 & \frac{R_{r} L_{a}}{L_{r} L_{s 1}} & \frac{R_{r} L_{a}}{L_{r} L_{s 2}} & -\left(\omega_{s}-\omega_{r}\right) & -\frac{R_{r}}{L_{r}}+\frac{R_{r} L_{a}}{L_{r}^{2}}
\end{array}\right]
$$

$B=\left[\begin{array}{llllll}1 & 0 & 0 & 0 & 0 & 0 \\ 0 & 1 & 0 & 0 & 0 & 0 \\ 0 & 0 & 1 & 0 & 0 & 0 \\ 0 & 0 & 0 & 1 & 0 & 0 \\ 0 & 0 & 0 & 0 & 0 & 0 \\ 0 & 0 & 0 & 0 & 0 & 0\end{array}\right]$.

$T_{s(1,2)}=\frac{R_{s(1,2)}}{L_{s(1,2)}}$ The stator time constant of the two stators.

$T_{r}=\frac{R_{r}}{L_{r}}$ The rotor time constant.
The fundamental equation of the movement of the DSIM is given by the expression Eq. (4):

$\frac{d \Omega}{d t}=\frac{1}{J}\left(T_{e m}-T_{l}-f_{f} \Omega\right)$.

The electromagnetic torque expressed as a function of the stator currents and rotor fluxes by

$T_{e m}=P \frac{L_{m}}{L_{m}+L_{r}}\left(\psi_{d r}\left(i_{q s 1}+i_{q s 2}\right)-\left(i_{d s 1}+i_{d s 2}\right) \psi_{q r}\right)$

where: $P$ is the number of poles pairs. 


\subsection{The MC model}

In the structure of the matrix converter, we can present two types: DMC and IMC. These types are based on the conversion matrix as the following modeling.

\subsubsection{DMC}

The MC is capable to connect to any input phase at any output phase through nine bidirectional switches four forces switching segments. Fig. 1 shows the diagram of MC.

The input currents are formed by the segments of the three output currents and the output voltages are created by the segments of the three input voltages. The mathematical model of MC is given by [8-11]:

$$
S_{i j}=\left[\begin{array}{lll}
S_{A a} & S_{A b} & S_{A c} \\
S_{B a} & S_{B b} & S_{B c} \\
S_{C a} & S_{C b} & S_{C c}
\end{array}\right]
$$

where $S_{j k}$ is the function of connection defined by the relation $S_{j k}=\left\{\begin{array}{l}1 \text { if the switch } S_{j k} \text { is on } \\ 0 \text { if the switch } S_{j k} \text { is off }\end{array}\right.$

$j \in\left\{\begin{array}{lll}A & B & C\end{array}\right\}, k \in\left\{\begin{array}{lll}a & b & c\end{array}\right\}$.

Only one switch each switching cell must be on.

$S_{j a}+S_{j b}+S_{j c}=1, j \in\{A, B, C\}$

The output voltage $V_{s}$ in any time presented as:

$$
V_{s}=\left[\begin{array}{c}
V_{A} \\
V_{B} \\
V_{C}
\end{array}\right]=\left[S_{j k}\right]\left[\begin{array}{c}
V_{a} \\
V_{b} \\
V_{c}
\end{array}\right] \text {. }
$$

The input MC currents $I_{i n}$ also defined as:

$$
I_{i n}=\left[\begin{array}{c}
I_{a} \\
I_{b} \\
I_{c}
\end{array}\right]=\left[S_{i j}\right]^{T}\left[\begin{array}{c}
I_{A} \\
I_{B} \\
I_{C}
\end{array}\right] \text {. }
$$

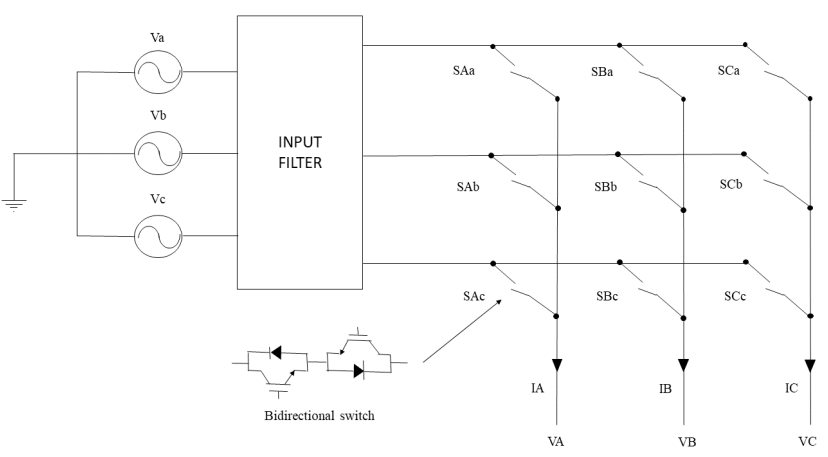

Fig. 1 Topology of DMC.

\subsubsection{IMC}

The IMC is described as a combination of a rectifier and a voltage inverter connected without dc-link capacitor as schematized in the Fig. 2. The rectifier formed via six bidirectional switches (S1-S6), and a classical inverter. Also, this type based on the direct conversion (AC to AC), but it distinguished by the the simplicity of control $[15,20,21]$.

Based on the indirect model, the conversion matrix is defined as the product of two conversion matrices on each side (rectifier and inverter) as written in Eq. (8).

$$
\begin{aligned}
{\left[\begin{array}{l}
V_{a} \\
V_{b} \\
V_{c}
\end{array}\right] } & =\left[\begin{array}{l}
S_{a p} S_{a n} \\
S_{b p} S_{b n} \\
S_{c p} S_{c n}
\end{array}\right] \cdot\left[\begin{array}{lll}
S_{A p} & S_{B p} & S_{C p} \\
S_{A n} & S_{B n} & S_{C n}
\end{array}\right] \cdot\left[\begin{array}{c}
V_{A} \\
V_{B} \\
V_{C}
\end{array}\right] \\
& =S_{i n v} \cdot S_{r e c} \cdot V_{i n}
\end{aligned}
$$

where $S_{i n v}, S_{r e c}$ are the conversion matrices of the inverter and rectifier based on the connexion functions of the IMC.

The space vector of output voltage $V_{o}$ defined by:

$V_{o}=\frac{2}{3}\left(V_{a}+V_{b} e^{j \frac{2 \pi}{3}}+V_{c} e^{j \frac{4 \pi}{3}}\right)$.

The space vector of the input current $I_{E}$ is specified by:

$I_{i n}=\frac{2}{3}\left(I_{A}+I_{B} e^{j \frac{2 \pi}{3}}+I_{C} e^{j \frac{4 \pi}{3}}\right)$.

The representation of the two space vectors is represented by Fig. 3 .

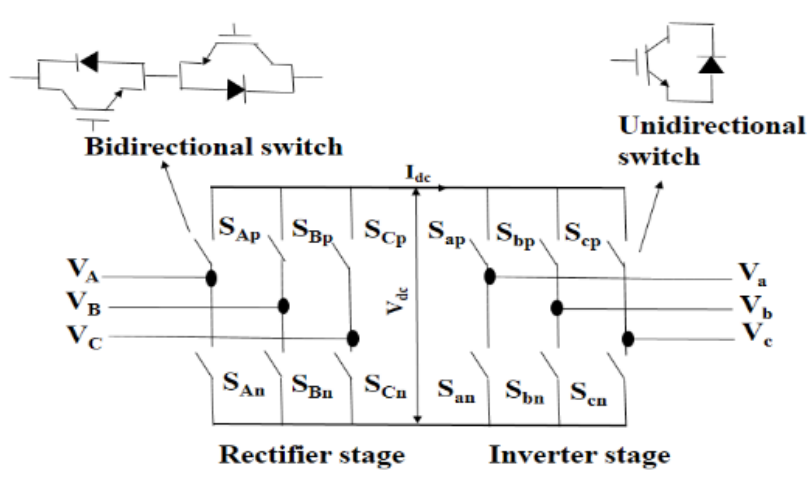

Fig. 2 Schematic of IMC.

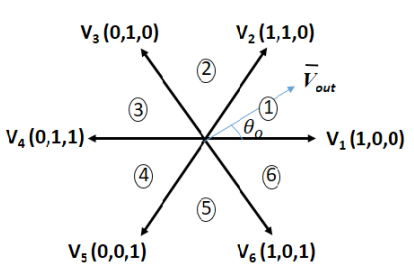

(a)

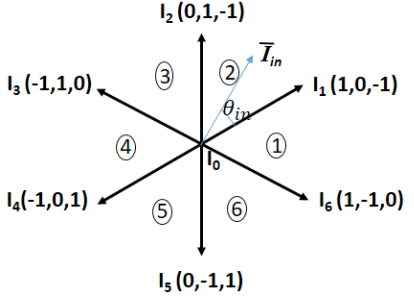

(b)
Fig. 3 The space vectors of IMC: (a) Output voltage, (b) Input current 


\section{A brief review of direct torque control of DSIM}

The DTC is based on the direct determination of the control sequence applied to the voltage inverter switches. This choice is generally based on the use of hysteresis comparators whose function is to control the state of the system, namely the amplitude of the stator flux and the electromagnetic torque, is established by the orientation of the stator flux as following $[18,19]$ :

$\varphi_{S 1,2}(t)=\int_{0}^{t}\left(V_{S 1,2}-R_{S 1,2} I_{S 1,2}\right) d t+\varphi_{S 1,2}(0)$.

By applying an active vector in the sampling period $\left[0, T_{e}\right]$, the voltage drop of the stator resistance $\left(R_{S 1,2} I_{S 1,2}\right)$ can be neglected with respect to the high-speed regions. Then Eq. (11) can be rewritten as follows:

$\varphi_{S 1,2}(t)=V_{S 1,2} T_{e}+\varphi_{S 1,2}(0)$.

The relationship between the stator voltage and the stator flux change can be established as follows:

$\Delta \varphi_{S 1,2}(t)=\varphi_{S 1,2}(t)-\varphi_{S 1,2}(0)=V_{S 1,2} T_{e}$.

The relation Eq. (13) means that the stator flux can be modified by applying a stator voltage for a time $T_{e}$. The end of the stator flow vector moves in the direction indicated by the voltage vector and performs a circular trajectory.

\subsection{Stator flux and torque estimation}

The estimation of the stator flux is generally carried out by the integration of the electromotive force factor. The stator flux components can be expressed using stator voltages and currents in the fixed reference $(\alpha, \beta)$ as follow $[6,7]$ :

$$
\left\{\begin{array}{l}
\varphi_{S_{\alpha 1,2}}=\int_{0}^{t}\left(V_{S_{\alpha 1,2}}-R_{S_{1,2}} I_{S_{\alpha 1,2}}\right) d t \\
\varphi_{S_{\beta 1,2}}=\int_{0}^{t}\left(V_{S_{\beta 1,2}}-R_{S_{1,2}} I_{S_{\beta 1,2}}\right) d t
\end{array}\right.
$$

The magnitude and the phase of stator flux is defined by:

$\left|\varphi_{S_{1,2}}\right|=\sqrt{\varphi_{S_{\alpha 1,2}}^{2}+\varphi_{S_{\beta 1,2}}^{2}}$

$\theta_{\varphi_{S 1,2}}=\operatorname{arctg}\left(\frac{\varphi_{S_{\beta 1,2}}}{\varphi_{S_{\alpha 1,2}}}\right)$.

Once the two flux components are obtained, the electromagnetic torque can be estimated from the following expression:

$\widehat{T_{e}}=P\left(\varphi_{S_{\alpha 1,2}} I_{S_{\beta 1,2}}-\varphi_{S_{\beta 1,2}} I_{S_{\alpha 1,2}}\right)$.

We can establish the classical table of the sequences below proposed by Takahashi to control the stator flux and the electromagnetic torque for the DSIM in Table 1.
Table 1 Switching table of DTC

\begin{tabular}{cccccccc}
\hline$\Delta \varphi_{s}$ & $\Delta T_{e}$ & $S_{1}$ & $S_{2}$ & $S_{3}$ & $S_{4}$ & $S_{5}$ & $S_{6}$ \\
\hline \multirow{4}{*}{1} & 1 & $V_{2}$ & $V_{3}$ & $V_{4}$ & $V_{5}$ & $V_{6}$ & $V_{1}$ \\
& 0 & $V_{7}$ & $V_{0}$ & $V_{7}$ & $V_{0}$ & $V_{7}$ & $V_{0}$ \\
& -1 & $V_{6}$ & $V_{1}$ & $V_{2}$ & $V_{3}$ & $V_{4}$ & $V_{5}$ \\
\hline \multirow{4}{*}{0} & 1 & $V_{3}$ & $V_{4}$ & $V_{5}$ & $V_{6}$ & $V_{1}$ & $V_{2}$ \\
& 0 & $V_{0}$ & $V_{7}$ & $V_{0}$ & $V_{7}$ & $V_{0}$ & $V_{7}$ \\
& -1 & $V_{5}$ & $V_{6}$ & $V_{1}$ & $V_{2}$ & $V_{3}$ & $V_{4}$ \\
\hline
\end{tabular}

\section{DTC for MC}

\subsection{DTC with DMC}

The DTC of DMC is based on Table 1, and the control of input power factor for fixed that to one, a hysteresis comparator is added to confirmed that, whatever is the sector which the input voltage vector is in, the MC takes any time two switching configurations with several directions for each VSI output vector selection by the classical DTC, this directions allows the possibility to control the input power factor by applied one to increase the angle and the second to decrease. The all probability switching configuration of MC used in DTC it gives in the Table 2, and the space vector diagram of output voltage and input current has been shown in Fig. 4 [14, 17, 18].

The overall diagram of DTC based on DMC is in Fig. 5.

Table 2 Switching table of DTC via DMC

\begin{tabular}{lcccccccccccc}
\hline $\begin{array}{l}\text { Sector } \\
\text { of } I_{i n}\end{array}$ & \multicolumn{1}{c}{1} & \multicolumn{2}{c}{2} & \multicolumn{2}{c}{3} & & 4 & & & & 6 \\
\hline$\Psi_{i}$ & +1 & -1 & +1 & -1 & +1 & -1 & +1 & -1 & +1 & -1 & +1 & -1 \\
$V_{1}$ & -3 & 1 & 2 & -3 & -1 & 2 & 3 & -1 & -2 & 3 & 1 & -2 \\
$V_{2}$ & 9 & -7 & -8 & 9 & 7 & -8 & -9 & 7 & 8 & -9 & -7 & 8 \\
$V_{3}$ & -6 & 4 & 5 & -6 & -4 & 5 & 6 & -4 & -5 & 6 & 4 & -5 \\
$V_{4}$ & 3 & -1 & -2 & 3 & 1 & -2 & -3 & 1 & 2 & -3 & -1 & 2 \\
$V_{5}$ & -9 & 7 & 8 & -9 & -7 & 8 & 9 & -7 & -8 & 9 & 7 & -8 \\
$V_{6}$ & 6 & -4 & -5 & 6 & 4 & -5 & -6 & 4 & 5 & -6 & -4 & 5 \\
\hline
\end{tabular}

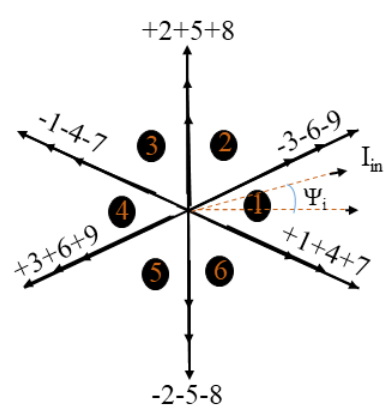

(a)

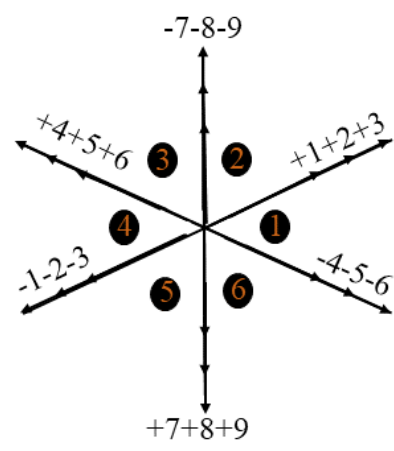

(b)
Fig. 4 Space vector of DMC: (a) Input current, (b) Output voltage 


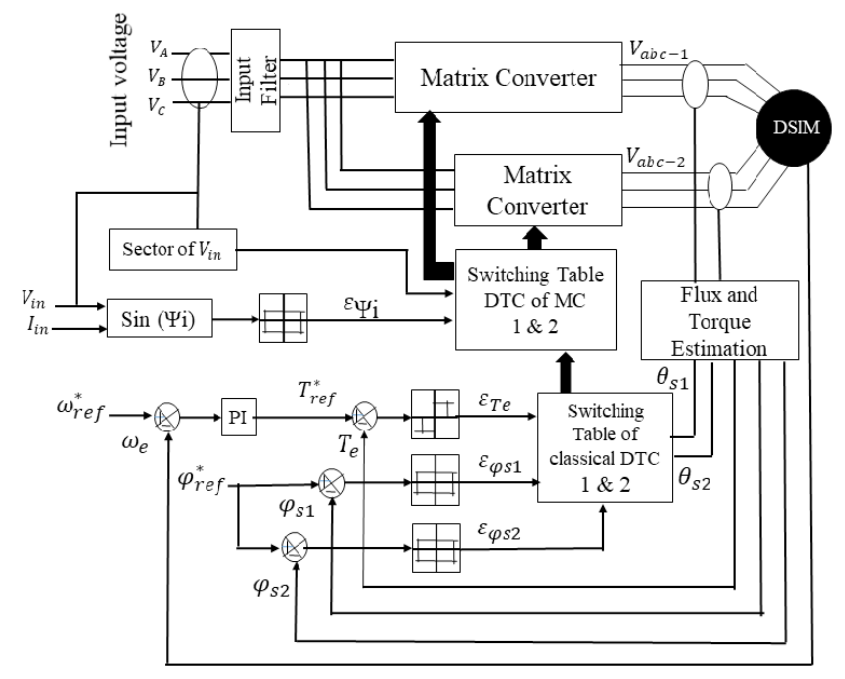

Fig. 5 DTC based on DMC.

\subsection{DTC with IMC}

This method suggested in [15], for the MC. It is rounded to the indirect model, which is describe the $\mathrm{MC}$ as a combination between two-stages a two-level inverter and a rectifier four quadrant, without dc-link capacitor [16].

The DTC used the IMC it is similar to the ISVM [9, 12], the SVM is used to control the virtual rectification stage for maximize the output voltage $V_{d c}$ and fixed the input power factor to one. In the other hand Table 2 is the inverter stage, which is describe before for control the torque and the flux of DSIM [22].

\subsubsection{Control of rectifier}

The purpose is to get the maximum output voltage $V_{d c}$ of the virtual rectifier and to fix the input power factor to one, based on SVM, the reference vector can be synthesized with these two adjacent vectors $I_{\gamma} I_{\delta}$, and a null vector $I_{0}$. Just like that

$$
I_{i n}=d \gamma I \gamma+d_{\delta} I_{\delta}
$$

Fig. 6 is illustrate that.

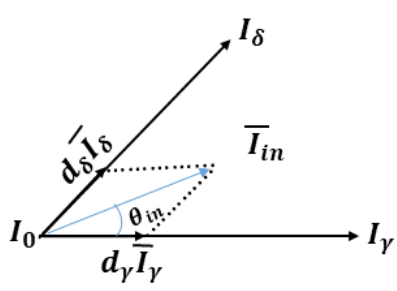

(a)

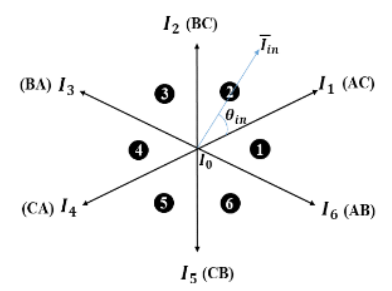

(b)
Fig. 6 Input current modulation for rectification stage
The duty cycles of all sector are determined in Eq. (18):

$$
\left\{\begin{array}{l}
d_{\gamma}=m_{c} \sin \left(\theta_{i n}\right) \\
d_{\delta}=m_{c} \sin \left(\frac{\pi}{3}-\theta_{i n}\right) \\
d_{0}=1-d_{\gamma}-d_{\delta}
\end{array}\right.
$$

where $m_{c}=\frac{\left|I_{i n}\right|}{I_{\text {rec }}}$ and $0 \prec \theta_{i n} \prec \frac{\pi}{3}$.

For maximize the voltage $V_{d c}$, the zero vector is remove. The two cyclic ratios are normalized according to Eq. $(20)[15,16]$ :

$$
\left\{\begin{array}{l}
d_{\gamma}^{\prime}=\frac{d_{\gamma}}{d_{\gamma}+d_{\delta}}=\frac{\sin \left(\theta_{i n}\right)}{\cos \left(\frac{\pi}{6}-\theta_{i n}\right)} \\
d_{\delta}^{\prime}=\frac{d_{\delta}}{d_{\delta}+d_{\gamma}}=\frac{\sin \left(\frac{\pi}{3}-\theta_{i n}\right)}{\cos \left(\frac{\pi}{6}-\theta_{i n}\right)} . \\
d_{0}=0 \quad \text { and } \quad d_{\gamma}^{\prime}+d_{\delta}^{\prime}=1
\end{array}\right.
$$

To guarantee the continuity of the current in the rectifier, the following condition must be respected.

$S_{a p}+S_{b p}+S_{c p}=1$

Respecting the relation (Eq. (20)), nine appropriate switching collections for rectifier can be utilized (Fig. 6 (b)). These Combinations are summed up in Table 3.

\subsubsection{Control of inverter}

For the inverter stage, the conventional DTC is applied according to the torque, flux and sector. The conventional DTC chooses the inverter vector that makes it conceivable to guarantee the regard bands of the error bands (flux and torque) [20-22].

The overall diagram of this technique is presented by Fig. 7 .

\section{Discussion and results}

With a view to compare, the performances of the two suggest techniques, the DTC with DMC and DTC with IMC are simulated with $4.5 \mathrm{KW}$ DSIM using Matlab/Simulink. The DTC structure applied to DSIM employ two hysteresis comparator for both the flux and torque. For the speed, we use a PI controller. The parameters used in this simulation are: $R_{s 1}=R_{s 2}=3.72 \Omega, R_{r}=2.12 \Omega, L_{s 1}=L_{s 2}=0.022 \mathrm{H}$, 
Table 3 Switching table of rectifier

\begin{tabular}{|c|c|c|c|c|c|c|c|c|c|}
\hline \multicolumn{2}{|c|}{ Vectors } & \multicolumn{2}{|c|}{ States } & $I_{a}$ & $I_{b}$ & $I_{c}$ & $\left|I_{E}\right|$ & $\theta_{i n}$ & $U_{r e c}$ \\
\hline \multirow{6}{*}{ 总 } & $I_{1}$ & & $\begin{array}{ll}0 & 0 \\
1 & 0\end{array}$ & $I_{r e c}$ & $-I_{r e c}$ & 0 & $\frac{2}{\sqrt{3}} I_{r e c}$ & $-\frac{\pi}{6}$ & $U_{a b}$ \\
\hline & $I_{2}$ & {$\left[\begin{array}{l}1 \\
0\end{array}\right.$} & $\begin{array}{ll}0 & 0 \\
0 & 1\end{array}$ & $I_{r e c}$ & 0 & $-I_{r e c}$ & $\frac{2}{\sqrt{3}} I_{r e c}$ & $\frac{\pi}{6}$ & $U_{a c}$ \\
\hline & $I_{3}$ & {$\left[\begin{array}{l}0 \\
0\end{array}\right.$} & $\begin{array}{ll}1 & 0 \\
0 & 1\end{array}$ & 0 & $I_{r e c}$ & $-I_{r e c}$ & $\frac{2}{\sqrt{3}} I_{r e c}$ & $\frac{\pi}{2}$ & $U_{b c}$ \\
\hline & $I_{4}$ & $\begin{array}{l}0 \\
1\end{array}$ & $\begin{array}{ll}1 & 0 \\
0 & 0\end{array}$ & $-I_{r e c}$ & $I_{r e c}$ & 0 & $\frac{2}{\sqrt{3}} I_{r e c}$ & $\frac{5 \pi}{6}$ & $U_{b a}$ \\
\hline & $I_{5}$ & $\begin{array}{l}0 \\
1\end{array}$ & $\begin{array}{ll}0 & 1 \\
0 & 0\end{array}$ & $-I_{r e c}$ & 0 & $I_{r e c}$ & $\frac{2}{\sqrt{3}} I_{r e c}$ & $-\frac{5 \pi}{6}$ & $U_{c a}$ \\
\hline & $I_{6}$ & $\begin{array}{l}0 \\
0\end{array}$ & $\begin{array}{ll}0 & 1 \\
1 & 0\end{array}$ & 0 & $-I_{r e c}$ & $I_{r e c}$ & $\frac{2}{\sqrt{3}} I_{r e c}$ & $-\frac{\pi}{2}$ & $U_{c b}$ \\
\hline \multirow{3}{*}{ 엉 } & \multirow{3}{*}{$I_{0}$} & & $\begin{array}{ll}0 & 0 \\
0 & 0\end{array}$ & 0 & 0 & 0 & 0 & 0 & 0 \\
\hline & & 0 & $\begin{array}{ll}1 & 0 \\
1 & 0\end{array}$ & 0 & 0 & 0 & 0 & 0 & 0 \\
\hline & & 0 & $\begin{array}{ll}0 & 1 \\
0 & 1\end{array}$ & 0 & 0 & 0 & 0 & 0 & 0 \\
\hline
\end{tabular}

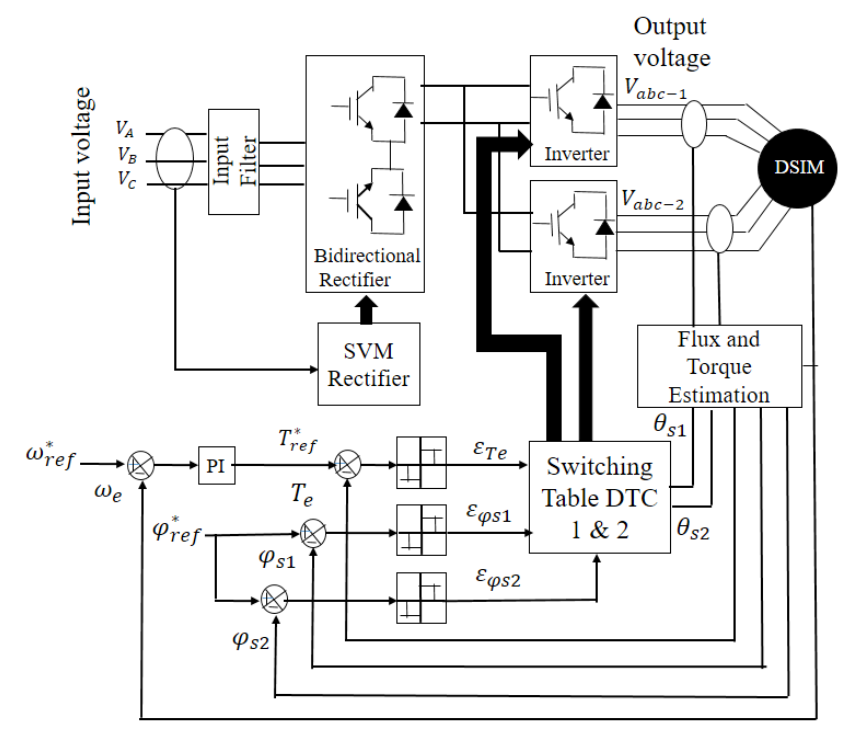

Fig. 7 DTC based on IMC.

$L_{r}=0.006 \mathrm{H}, L_{m}=0.3672 \mathrm{H}, J=0.0625 \mathrm{Kg} \cdot \mathrm{m}^{2}$, $K_{f}=0.001 \mathrm{Nm} \cdot \mathrm{s} / \mathrm{rad}$.

From the analysis of simulation results of the two DTC, we can comment the following points:

- The machine's speed pursues exactly its set point, also when the load torque is varied as shown in Fig. 8 for both techniques, although the DTC of IMC faster than DMC.

- Fig. 9 presents the electromagnetic torque for two DTC, the couple is equal to the load torque in steady state and respect its band for two DTC, but in the transient steady the DTC of DMC its contain some overshot of its band.

- The flux as well follows its reference and respects its hysteresis band for both DTC Figs. 10 and 11. Other than when changing the direction of rotation, we can remark some overshot, and the DTC of IMC is less ripple than DMC.

- Figs. 12 and 13 show the output current, which is sinusoidal forms, and changed their amplitude and

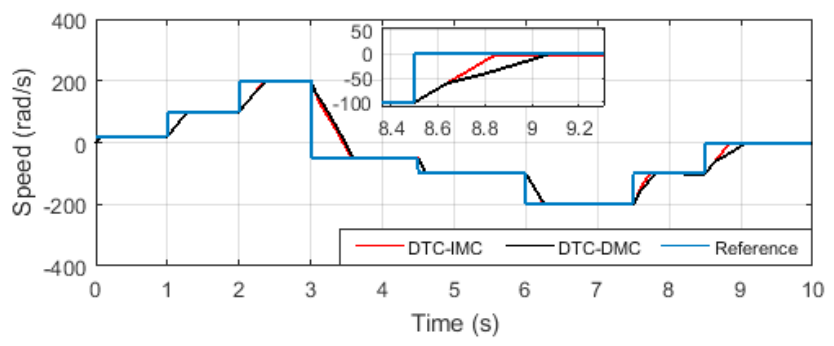

Fig. 8 Speed and its reference

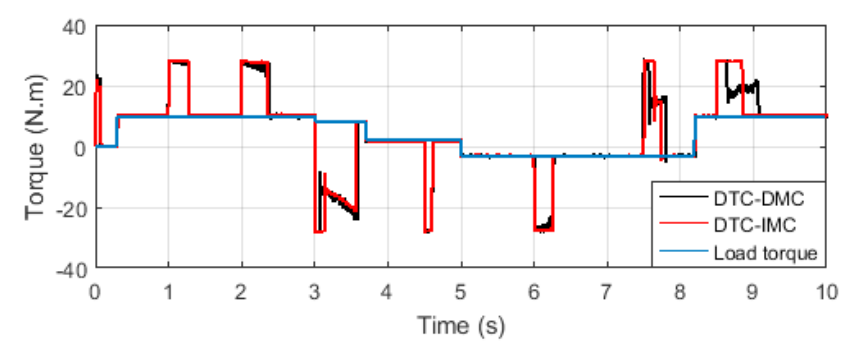

Fig. 9 Electromagnetic torque

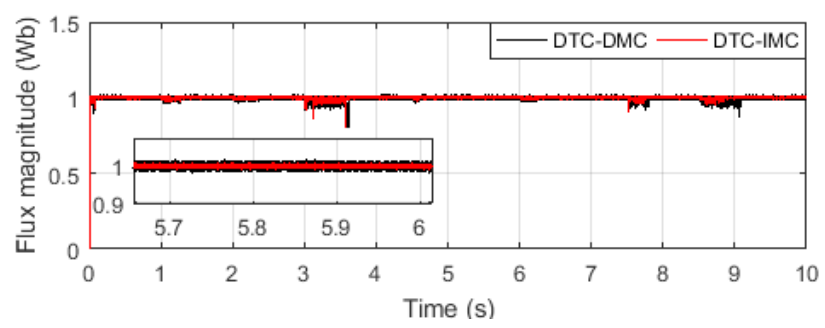

Fig. 10 Stator flux magnitude

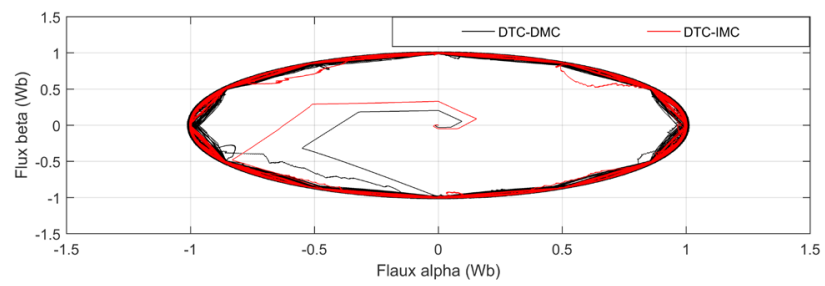

Fig. 11 Stator flux vector 


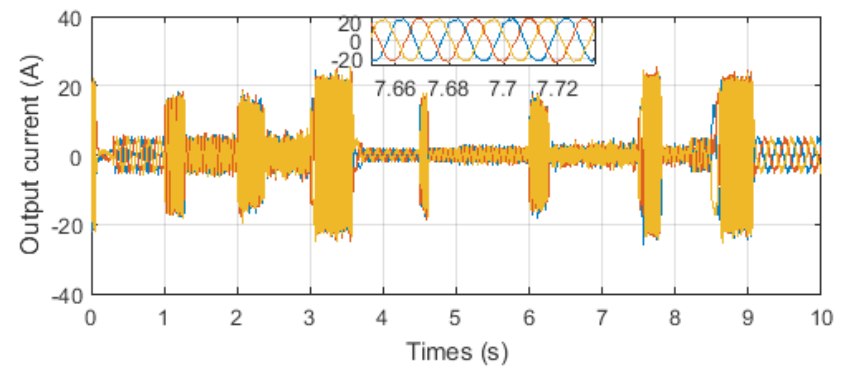

Fig. 12 Output currents with DMC

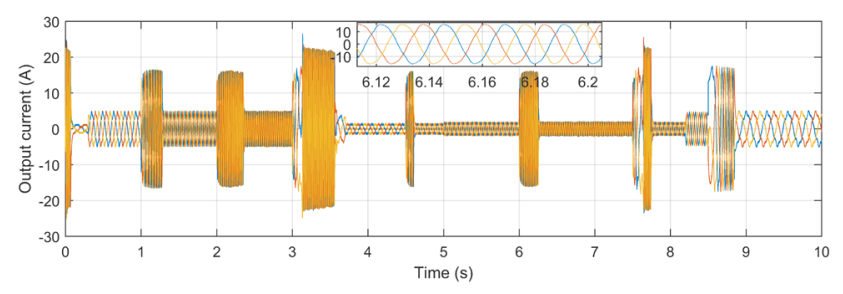

Fig. 13 Output currents with IMC

frequency according to speed reference and load torque and, we can see the form of current for IMC it's better compared to DMC, and less harmonic.

- The output voltage in both Figs. 14 and 15, its changed according the frequency and the load torque in two DTC. Then the DTC based on IMC it give best form and low harmonics.

- The input voltage and both the unfiltered and the filtered current Figs. 16, 17, 18 and 19, it is in phase, that is to say the operation with unity of power factor, and we can remark the highest quality and low harmonics in the DTC of IMC Figs. 20, 21, 22 and 23 , because the fictive rectifier, is switching by constant frequency (SVM).

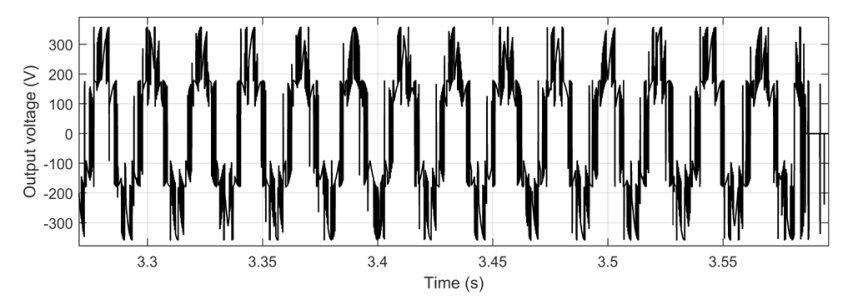

Fig. 14 Output voltage of DMC

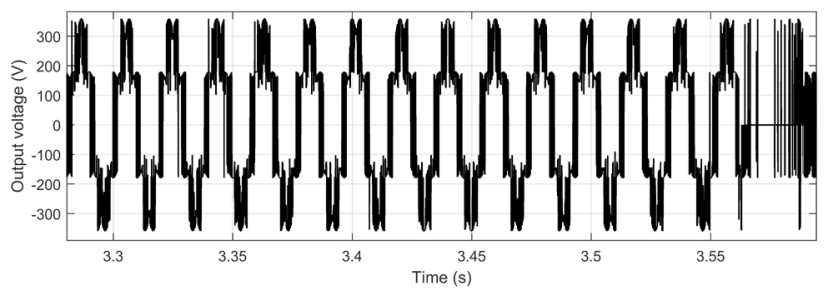

Fig. 15 Output voltage of IMC

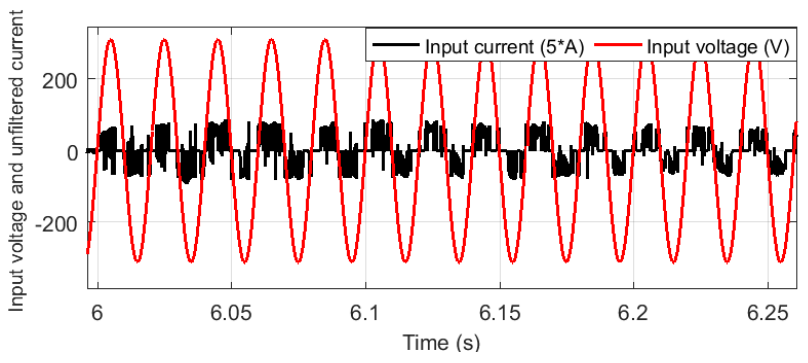

Fig. 16 Unfiltered input current and voltage of DMC

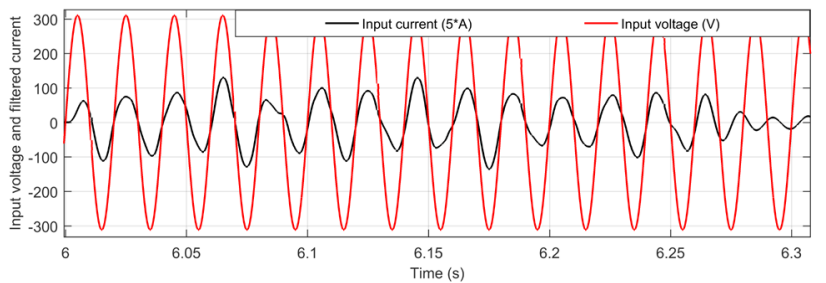

Fig. 17 Input voltage and filtered current of DMC

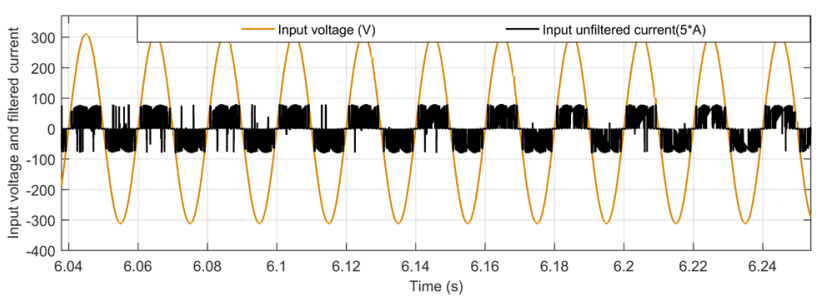

Fig. 18 Input voltage and unfiltered current of IMC

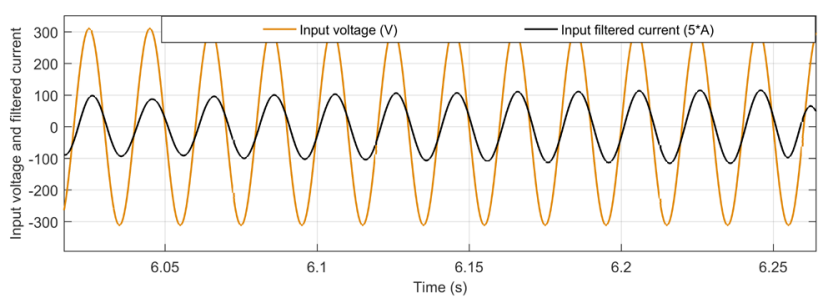

Fig. 19 Input voltage and filtered current of IMC

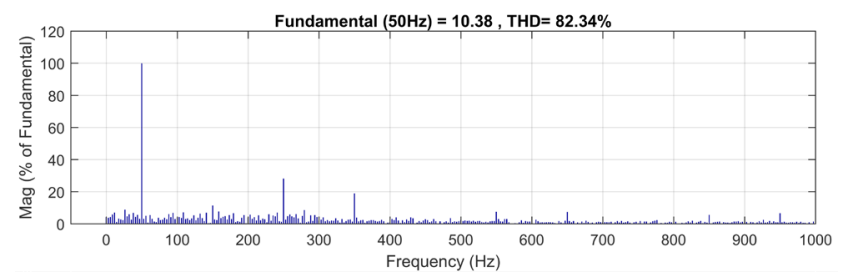

Fig. 20 Harmonic spectrum of input unfiltered current of DMC

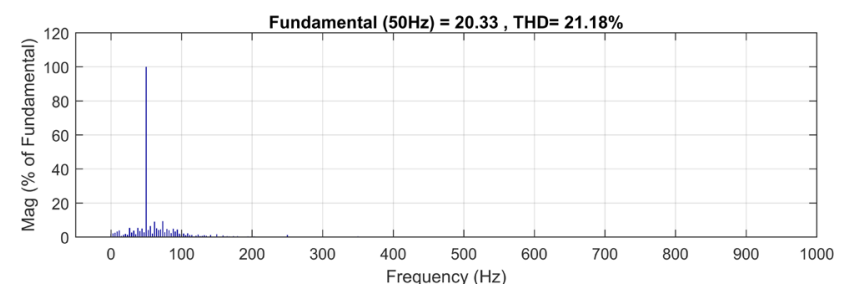

Fig. 21 Harmonic spectrum of input filtered current of DMC 


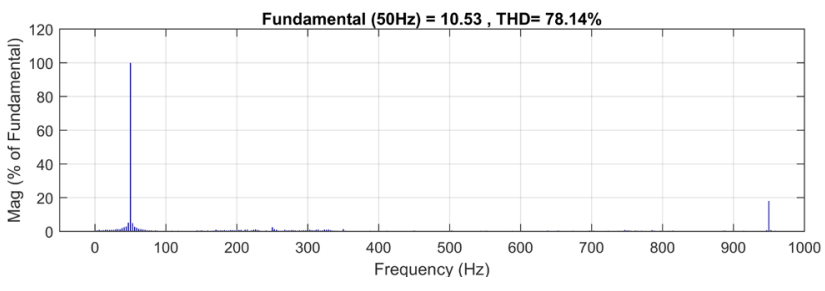

Fig. 22 Harmonic spectrum of input unfiltered current of IMC

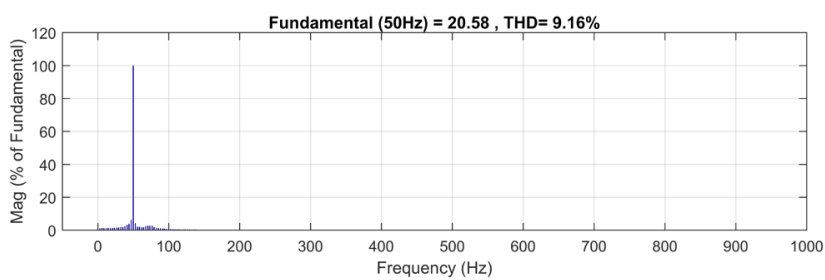

Fig. 23 Harmonic spectrum of input filtered current of IMC

- The results obtained with the IMC are in general, better than those obtained with DMC.

- From the point of view of electrical performance, the two control give a sinusoidal output current.

\section{References}

[1] Holakooie, M. H., Ojaghi, M., Taheri, A. "Modified DTC of a Six-Phase Induction Motor With a Second-Order Sliding-Mode MRAS-Based Speed Estimator", IEEE Transactions on Power Electronics, 34(1), pp. 600-611, 2019. https://doi.org/10.1109/TPEL.2018.2825227

[2] Levi, E. "Multiphase Electric Machines for Variable-Speed Applications", IEEE Transactions on Industrial Electronics, 55(5), pp. 1893-1909, 2008.

https://doi.org/10.1109/TIE.2008.918488

[3] Barrero, F., Duran, M. J. "Recent Advances in the Design, Modeling, and Control of Multiphase Machines-Part I", IEEE Transactions on Industrial Electronics, 63(1), pp. 449-458, 2016. https://doi.org/10.1109/TIE.2015.2447733

[4] Duran, M. J., Barrero, F. "Recent Advances in the Design, Modeling, and Control of Multiphase Machines-Part II", IEEE Transactions on Industrial Electronics, 63(1), pp. 459-468, 2016. https://doi.org/10.1109/TIE.2015.2448211

[5] Takahashi, I., Noguchi, T. "A New Quick-Response and HighEfficiency Control Strategy of an Induction Motor", IEEE Transactions on Industry applications, IA-22(5), pp. 820-827, 1986. https://doi.org/10.1109/TIA.1986.4504799

[6] Bojoi, R., Farina, F., Griva, G., Profumo, F., Tenconi, A. "Direct torque control for dual three-phase induction motor drives", IEEE Transactions on Industry Applications, 41(6), pp. 1627-1636, 2005. https://doi.org/10.1109/TIA.2005.858281

[7] Pandit, J. K., Aware, M. V., Nemade, R. V., Levi, E. "Direct Torque Control Scheme for a Six-Phase Induction Motor With Reduced Torque Ripple", IEEE Transactions on Power Electronics, 32(9), pp. 7118-7129, 2017.

https://doi.org/10.1109/TPEL.2016.2624149
In transient mode, the peak of the current varies from one control to the other.

\section{Conclusion}

In the present work, a comparative survey between the performances of two techniques control of DSIM namely the DTC with direct and indirect matrix converter has been presented. The two techniques are simulated in Matlab/Simulink environment for a $4.5 \mathrm{~kW}$ DSIM and with similar references of flux and speed. The simulation results obtained illustrate that the DTC with IMC is superior to the DTC with DMC, it yields good electrical and electromagnetic execution such as the stator flux, electromagnetic torque, and total harmonic distortion of input current in all operating conditions. Furthermore, the use of the IMC simplifies significantly the control scheme and makes its implementation easier.

[8] Taheri, A. "Harmonic reduction of Direct Torque Control of sixphase induction motor", ISA Transactions, 63, pp. 299-314, 2016. https://doi.org/10.1016/j.isatra.2016.02.014

[9] Wheeler, P. W., Rodriguez, J., Clare, J. C., Empringham, L., Weinstein, A. "Matrix converters: A technology review", IEEE Transactions on Industrial Electronics, 49(2), pp. 276-288, 2002. https://doi.org/10.1109/41.993260

[10] Rodriguez, J., Rivera, M., Kolar, J. W., Wheeler, P. W. "A Review of Control and Modulation Methods for Matrix Converters", IEEE Transactions on Industrial Electronics, 59(1), pp. 58-70, 2012. https://doi.org/10.1109/TIE.2011.2165310

[11] Venturini, M. "A new sine wave in sine wave out, conversion technique which eliminates reactive elements", Proceedings of POWERCON, 7, pp. E3.1-E3.15, 1980.

[12] Alesina, A., Venturini, M. G. B. "Analysis and design of optimum-amplitude nine-switch direct AC-AC converters", IEEE Transactions on Power Electronics, 4(1), pp. 101-112, 1989. https://doi.org/10.1109/63.21879

[13] Huber, L., Borojevic, D. "Space vector modulated three-phase to three-phase matrix converter with input power factor correction", IEEE Transactions on Industry Applications, 31(6), pp. 1234-1246, 1995.

https://doi.org/10.1109/28.475693

[14] Wang, X., Lin, H., She, H., Feng, B. "A Research on Space Vector Modulation Strategy for Matrix Converter Under Abnormal InputVoltage Conditions", IEEE Transactions on Industrial Electronics, 59(1), pp. 93-104, 2012.

https://doi.org/10.1109/tie.2011.2157288 
[15] Casadei, D., Serra, G., Tani, A. "The use of matrix converters in direct torque control of induction machines", IEEE Transactions on Industrial Electronics, 48(6), pp. 1057-1064, 2001.

https://doi.org/10.1109/41.969384

[16] Li, Y., Liu, W. "A Novel Direct Torque Control Method for Induction Motor Drive System Fed by Two-stage Matrix Converter with Strong Robustness for Input Voltage", In: 2007 2nd IEEE Conference on Industrial Electronics and Applications, Harbin, China, 2007, pp. 698-702. https://doi.org/10.1109/iciea.2007.4318496

[17] Faraji, V., Aghasi, M., Khaburi, D. A., Kalantar, M. "Direct torque control with improved switching for induction motor drive system fed by indirect matrix converter", In: National Conference on Electrical, Electronics and Computer Engineering, Bursa, Turkey, 2010, pp. 309-314.

[18] Kianinezhad, R., Seyfossadat, S. G., Talaeizadeh, V., Hasani, A. "A new DTC of six phase induction machines using matrix converter", In: 2009 International Conference on Advances in Computational Tools for Engineering Applications, Zouk Mosbeh, Lebanon, 2009, pp. 127-132.

https://doi.org/10.1109/actea.2009.5227862

[19] Talaeizadeh, V., Kianinezhad, R., Seyfossadat, S. G., Shayanfar, H. A. "Direct torque control of six-phase induction motors using three-phase matrix converter", Energy Conversion and Management, 51(12), pp. 2482-2491, 2010.

https://doi.org/10.1016/j.enconman.2010.05.011
[20] Meroufel, A., Massoum, S., Bentaallah, A., Wira, P., Belaimeche, F. Z., Massoum, A. "Double star induction motor direct torque control with fuzzy sliding mode speed controller", Revue Roumaine des Sciences Techniques-Serie Electrotechnique et Energetique, 62(1), pp. 31-35, 2017

[21] Moati, Y, Kouzi, K., Bencherif, A., Bensaoucha, S. "New Design of Neural Direct Power Control of DSIM Fed by Indirect Matrix Converter", In: Hatti, M. (ed.) Renewable Energy for Smart and Sustainable Cities, ICAIRES 2018, Lecture Notes In Networks and Systems, Vol. 62, Springer, Cham, Switzerland, 2018, pp. 216-224. https://doi.org/10.1007/978-3-030-04789-4_24

[22] Yahia, M., Katia, K., Khalil, M, Saddam, B "Direct Torque Control to Improve the Performances of the DSIM Powered by Indirect Matrix Converter", In: 2018 International Conference on Communications and Electrical Engineering (ICCEE), El Oued, Algeria, 2018, pp. 1-5. https://doi.org/10.1109/CCEE.2018.8634447 